\title{
Therapeutic Potency of Gallium verum Extract on Ethanol-Induced Gastric Ulcer in Rats
}

\author{
Bassant Mohamed Mohamed Lotfy ${ }^{1}$ (D), Mohamed R. Mousa ${ }^{2}$ (D), Mona Samir Fawzy \\ El-Sayed El-Shehry ${ }^{3(D)}$, Salma Hussein Abdel-Fattah Ahmed ${ }^{4}$ (D), Sara Bayoumi Ali ${ }^{(D)}$, Abdeljalil \\ Mohamed Al Shawoush 6 (D), Ayman Saber Mohamed 7,* (D)
}

1. Biotechnology Department -Faculty of biotechnology- October University for Modern Sciences and Arts (MSA) - Egypt; Bassant.mohamed3@msa.edu.eg (B.M.M.L.);

2. Department of Pathology, Faculty of Veterinary Medicine, Cairo University, Giza, 12211, Egypt; Mohamedrefat850@gmail.com (M.R.M.);

3. Biotechnology Department -Faculty of biotechnology- October University for Modern Sciences and Arts (MSA) - Egypt; monaelshehry11@gmail.com (M.S.F.E.-S.E-S.);

4. Biotechnology Department -Faculty of biotechnology- October University for Modern Sciences and Arts (MSA) - Egypt; salma.hussein2@msa.edu.eg (S.H.A.-F.A.);

5. M.Sc. - Zoology Department - Faculty of Science - Cairo University, Egypt; .sara.bayoumi@ yahoo.com (S.B.A.);

6. M.Sc. Zoology Department - Faculty of Science - Cairo University 12613, Giza, Egypt; sedra200713@yahoo.com (A.M.A.S.);

7. Lecturer of Physiology- Zoology Department - Faculty of Science - Cairo University-12613, Giza, Egypt; ayman81125@hotmail.com (A.S.M.);

* Correspondence: ayman81125@hotmail.com (A.S.);

Scopus Author ID 56564677600

Received: 28.07.2021; Revised: 22.09.2021; Accepted: 25.09.2021; Published: 4.11.2021

Abstract: Gallium verum, lady's bedstraw is an herbaceous annual plant belonging to the genus Rubiaceae; it possessed antioxidant, cytotoxic for cancer cells, antimicrobial, protective and endocrine effects. This work aimed to investigate the curative effects of G. verum extract on gastric ulcers following absolute ethanol administration in the healthy rat. Eighteen rats were randomly divided into three main groups; rats were fastened for 24 hours before ethanol administration. All groups except control administered ethanol ( $5 \mathrm{ml} / \mathrm{kg}$ body weight; orally). The rats were administrated distilled water (Ulcer group) or G. verum extract $(100 \mathrm{mg} / \mathrm{kg})$ one hour later. G. verum extract caused a significant decrease in ulcer index, gastric juice volume, malondialdehyde, and nitric oxide, while gastric juice $\mathrm{pH}$, glutathione, glutathione-S-transferase, and catalase increased significantly. The histological lesion score showed a significant enhancement in group G. verum compared to the ulcer group that scored the highest pathological destruction score. Immunohistochemical markers of NF- $\mathrm{kB}$ p65 and TNF- $\alpha$ showed a significant decrease in G. verum group. G. verum extract is a promising treatment modality against gastric injury through its powerful antioxidant, acid neutralizing, healing promotion, and antinflammation effects.

Keywords: Gallium verum; gastric ulcer; immunohistology; antioxidant; anti-inflammatory

(C) 2021 by the authors. This article is an open-access article distributed under the terms and conditions of the Creative Commons Attribution (CC BY) license (https://creativecommons.org/licenses/by/4.0/).

\section{Introduction}

Gastric ulcer (GU) is a growing public health concern worldwide [1]. Traditionally, GU is characterized as pepsin and hydrochloric acids mucosal split and corrosive action [2]. Most cases of GU resulted from stress, alcohol consumption, smoking, Helicobacter pylori, and nonsteroidal anti-inflammatory drugs (NSAIDs) $[3,4]$. In the gastrointestinal tract, alcohol 
exposure can damage the motility of the esophagus, stomach, and gut and the capacity of gut absorption [5]. It can generate mucosal damage and even carcinogenesis [2].

Recently, ethanol has been applied orally in experimental animals to cause acute gastric lesions and ulcers, which is considered a harmful agent associated with multiple pathologies [6]. Ethanol affects the mucosal barrier of the stomach, causing increased mucosal permeability and bleeding [7]. In the treatment of GU, various classes of synthetic medications are used as proton pump inhibitors (omeprazole), prostaglandin analogs, and $\mathrm{H}_{2}$ receptor blockers (cimetidine, ranitidine, and famotidine), but many of these medicines have significant side effects such as arrhythmias, gynecomastia, impotence, arthralgia, hypergastrinemia, and hemopoietic changes [8]. Efforts to discover new drugs with lower costs and fewer side effects are necessary. Subsequently, treatment with natural products is now considered an alternative approach to controlling the disease $[9,10]$. Traditionally, using natural products with therapeutic properties is considered as ancient as human civilization. For a long time, mineral, plant, and animal products were the main sources of treatments for therapeutic purposes $[11,12]$. The use of herbal medicine to treat major illnesses as a drug treatment has shown to be clinically beneficial and less relatively harmful than existing medications and often decreases the aggressive factors that function as a guide for GU prevention [14]. Herbal medicine is commonly used in developing countries for primary health care because of greater acceptability, compliance with the human body, and lower side effects [15]. The chemical elements in the plant extracts are part of the biochemical processes of living flora and are thus more consistent with the human body [8]. Galium verum (G. verum, lady's bedstraw) is a perennial herbaceous plant belonging to the Rubiaceae family and has been extensively documented throughout history due to its various therapeutic properties. Previous studies have reported that $G$. verum has been used as a sedative, an anticancer agent, in treating gout, epilepsy [16], liver disorders, and cardiovascular diseases [17].

Hence, the present study aimed to assess the gastroprotective mechanisms of G. verum in rats.

\section{Material and methods}

\subsection{Chemicals.}

Ethanol 100\%, 80\% methanol, and all biochemical kits were purchased from the Biodiagnostic Company (El Moror St, Dokki, Egypt). Dried G.verum herb was purchased from Shender Group, LTD, UK.

\subsection{Preparation of G. verum extract.}

According to Lakić et al. [7] method with some modification, air-dried G.verum $L$ was ground (sieve 0.75) and macerated at room temperature for $24 \mathrm{~h}$ in $80 \%$ methanol $(\mathrm{MeOH})$ (1:5 w/v, $100 \mathrm{~g}$ dried G.verum $L)$. Methanolic G.verum $L$ mixture was filtered through (Whatman, No.1) after maceration and evaporated to dryness under reduced pressure. The residue $(5 \mathrm{~g})$ was stored at $-30^{\circ} \mathrm{C}$ in a dark glass bottle.

\subsection{Phytochemical qualitative analysis.}

The plant extracts were assessed for the existence of the phytochemical activity by using the following standard methods [18-22]. 
2.3.1. Detection of phenols.

G. verum extract was spotted on a filter paper. A drop of phosphomolybdic acid reagent was added to the spots and was exposed to ammonia vapors. The blue coloration of the spots indicates the presence of phenols.

\subsubsection{Detection of tannins.}

To 2-3 $\mathrm{ml}$ of G. verum extract, $10 \%$ alcoholic ferric chloride solution was added. The dark blue or greenish-grey coloration of the solution indicates the presence of tannins in the extracts.

\subsubsection{Detection of alkaloids.}

A drop of G. verum extract prepared in methanol was spotted in a small piece of precoated TLC plate, and the plate was sprayed with Dragendorff's reagent. The orange coloration of the spot indicates the presence of alkaloids.

\subsubsection{Detection of anthraquinones.}

About $50 \mathrm{mg}$ of the G. verum extract was heated with ferric chloride (10\%) and $1 \mathrm{ml}$ of conc. $\mathrm{HCl}$. After colling, the filtrates were shaken with diethyl ether. The ether extract was further extracted with conc. ammonia. The pink or deep red coloration of the aqueous layer indicates the presence of anthraquinones.

\subsubsection{Detection of saponins.}

$10 \mathrm{mg}$ of G. verum extract was mixed with hot water, and the mixtures were shaken for $0.5 \mathrm{~min}$. The formation of stable foam indicates the presence of saponins.

\subsubsection{Detection of flavonoids.}

$2 \mathrm{ml}$ of $G$. verum extract, a piece of magnesium ribbon and $1 \mathrm{ml}$ of con. HCL were added. The Pink-red or red coloration of the solution indicates the presence of flavonoids.

\subsubsection{Cardiac glycosides (Keller-Killani test).}

$5 \mathrm{~mL}$ extract was treated with $2 \mathrm{~mL}$ glacial acetic acid plus 1-drop ferric chloride solution. Then $1 \mathrm{ml}$ of conc. sulfuric acid (90\%) was added. A deoxysugar characteristic of cardiac glycosides is indicated by a brown ring at the contact.

\subsubsection{Test for steroids.}

Chloroform (1ml) and conc. sulfuric acid ( $1 \mathrm{ml})$ was added with the $2.5 \mathrm{ml}$ of G. verum extract. A red hue emerged in the bottom chloroform layer, indicating the presence of steroids.

2.3.9. Test for iridoids.

$1 \mathrm{~mL}$ of Trim-Hill reagent was added to the concentrated extract and then heated for a few minutes. A blue-green or red color indicated the presence of iridoids. 


\subsection{Experimental animals.}

Male albino Wistar rats (Rattus norvegicus) weighing $200 \mathrm{gm}$ were used in this study. The rats were obtained from the National Research Center (NRC, Dokki, Giza). They were grouped and housed in polyacrylic cages (six animals per cage) in the well-ventilated animal house of the Zoology Department, Faculty of Science, Cairo University. Rats were given food and water ad libitum. Rats were maintained in a friendly environment of a $12 \mathrm{hr} / 12 \mathrm{hr}$ lightdark cycle at room temperature $\left(22-25^{\circ} \mathrm{C}\right)$. They were acclimatized to laboratory conditions for 7 days before the commencement of the experiment.

\subsection{Ethical consideration.}

The study's experimental protocols and procedures were approved by the Cairo University, Faculty of Science, Institutional Animal Care and Use Committee (IACUC) (Egypt). All the experimental procedures were carried out in accordance with international guidelines for the care and use of laboratory animals.

\subsection{Acute toxicity study $\left(L D_{50}\right)$.}

$\mathrm{LD}_{50}$ of Gallium verum was determined according to the method described by Chinedu et al. [23]. The animals have fasted for $12 \mathrm{hrs}$ before the experiments then divided into 5 groups (2 animals /group). G. verum extract was given at concentrations 10, 100, 300, and $600 \mathrm{mg} / \mathrm{kg}$. The animals have been observed $24 \mathrm{hrs}$ for death and behavior changes. $\mathrm{LD}_{50}$ calculated from the following equation:

$$
\mathrm{LD}_{50}=\left(\mathrm{M}_{1}+\mathrm{M}_{0}\right) / 2=(600+300) / 2=450 \mathrm{mg} / \mathrm{kg}
$$

where $\mathrm{M}_{0}$ is the maximum dose of $G$. verum that did not result in death.; $\mathrm{M}_{1}$ is the lowest dose of G. verum that caused mortality.

\subsection{Experimental design.}

After one week of acclimatization, 18 rats were assigned into three main groups (6 rats/group). The rats were fastened for 24 hours before initiating the experiment.

Control group: rats administered distilled water $(5 \mathrm{ml} / \mathrm{kg}$ body weight; orally), followed by distilled water one hour later.

Ulcer group: rats administered ethanol ( $5 \mathrm{ml} / \mathrm{kg}$ body weight; orally), followed by distilled water one hour later.

G. verum: rats administered $99 \%$ ethanol ( $5 \mathrm{ml} / \mathrm{kg}$ body weight; orally), followed by G. verum $(45 \mathrm{mg} / \mathrm{Kg}$ body weight; orally) one hour later.

\subsection{Animal handling and specimen collection.}

After the end of all experiments, the rats were fully anesthetized with $3 \%$ sodium pentobarbital $[24,25]$. Then, the stomach was removed and immediately blotted using filter paper. Part of the stomach was stored at $-80^{\circ} \mathrm{C}$ for biochemical analysis. Another part of the stomach was suspended in $10 \%$ formal saline for fixation preparatory to histopathological examination [26]. 


\subsection{Stomach homogenate preparation.}

Stomach tissues were homogenized $(10 \% \mathrm{w} / \mathrm{v})$ in ice-cold $0.1 \mathrm{M}$ Tris- $\mathrm{HCl}$ buffers $(\mathrm{pH}$ 7.4). The homogenate was centrifuged at $3000 \mathrm{rpm}$ for $15 \mathrm{~min}$., at $4^{\circ} \mathrm{C}$, and the resultant supernatant was used for the biochemical analyses [27].

\subsection{Ulcer markers.}

The gastric juice collected after opening the stomachs was centrifuged at $3000 \mathrm{rpm}$ for 10 minutes to remove any solid remnants, and the volume of the supernatant was measured. The $\mathrm{pH}$ of gastric juice was determined using a $\mathrm{pH}$ meter. The stomachs were examined for ulcers under magnification (x10). The ulcer index was assessed as follows: if the ulcer length is: $<1.0 \mathrm{~mm}=1$ point, between 1 and $2 \mathrm{~mm}=2$ point, $\geq 3 \mathrm{~mm}=3$ point. The sum of the scores was divided by 10 (magnification of the lens) to obtain the ulcer index in rats [28].

\subsection{Oxidative Stress Markers Assessment.}

Malondialdehyde (MDA) was estimated as an index of lipid peroxidation [24], glutathione reduced (GSH), nitric oxide (NO), glutathione-S-transferase (GST), and catalase were determined in the stomach homogenate supernatant according to the manufactures instructions using Biodiagnostic kits (Giza, Egypt).

\subsection{Histopathologic study analyses.}

Stomach samples were fixed in $10 \%$ formal saline. Then, the paraffin-embedded sections were prepared and cut into $5 \mu \mathrm{m}$ thick sections in a rotary microtome. Tissue sections were stained with the hematoxylin-eosin dye (H\&E) and evaluated for histopathological alterations.

\subsection{Immunohistochemistry.}

Tissue sections of stomach samples were cut into positively charged slides and rehydrated to distilled water. Antigen retrieval and blocking for both endogenous peroxidases and protein were also performed. Tissue sections were washed in PBS and incubated overnight at $4{ }^{\circ} \mathrm{C}$ with primary anti- NF- $\kappa$ B p65 and anti- TNF- $\alpha$ antibodies (Santa Cruz, Biotechnology, Inc. at a dilution of 1:100). After washing, tissue slides were incubated with HRP-labelled secondary antibody (Abcam, UK. At a dilution of 1:1000). A dab-substrate kit (Thermo Fisher Scientific) was used to develop the color. Finally, the slides were counter-stained using Meyers hematoxylin. Control negative slides were obtained by deletion of the primary antibody step. Positive expression was quantified as area \% using CellSens dimensions software (Olympus, Japan).

\subsection{Statistical significance.}

All Values were expressed as means \pm standard error of the mean (SEM). The comparisons within groups were evaluated using one-way analysis of variance (ANOVA) with Duncan post hoc test to compare the group means, and $\mathrm{p}<0.05$ was considered statistically significant. SPSS for Windows (version 15.0) was used for the statistical analysis. 


\section{Results and Discussion}

\subsection{Phytochemical qualitative analysis.}

Data recorded in Table 1 demonstrated the determination of compounds from G. verum $L$ extract. The extract contains flavonoids, anthraquinones, tannins, iridoids, triterpenes, steroids, phenols, and saponins, while it was free of cardiac glycosides and alkaloids. Conventional medicines have been used to treat gastric ulcers for a long time. Accordingly, many natural products have been examined for their anti-ulcerogenic effects [29]. In this way, G. verum has proved to be beneficial, and it has been widely used throughout history as it possesses antioxidant, cytotoxic for cancer cells, antimicrobial, protective and endocrine effects.

Table 1. Quantitative determination of compounds from $G$. verum L extract.

\begin{tabular}{c|c} 
Test & G. verum extract \\
\hline Flavonoids & ++ \\
\hline Anthraquinones & ++ \\
\hline Tannins & ++ \\
\hline Iridoids & ++ \\
\hline Triterpenes & ++ \\
\hline Steroids & ++ \\
\hline Phenols & + \\
\hline Saponins & + \\
\hline Cardiac Glycosides & - \\
\hline Alkaloids & - \\
(-) negative reaction, + positive reaction,,++ strong positive reaction.
\end{tabular}

3.2. The curative potency of G. verum on juice volume, juice index, and $p H$ of gastric ulcer in rats.

The data in Table 1, in addition to stomach ultrastructure in Figure 1, indicate that gastric juice volume and ulcer index were significantly increased $(\mathrm{P}<0.05)$ while the $\mathrm{pH}$ was significantly decreased $(\mathrm{P}<0.05)$ in the ulcer group compared with the corresponding control group..

Table 2. Curative effect of $G$. verum on gastric ulcer markers in rats.

\begin{tabular}{c|c|c|c} 
Groups & Gastric juice $\mathbf{~ p H}$ & Gastric juice volume (ml) & Gastric ulcer index \\
\hline Control & $3.80 \pm 0.22^{\mathrm{b}}$ & $1.33 \pm 0.13^{\mathrm{a}}$ & $0.44 \pm 0.12^{\mathrm{a}}$ \\
\hline Ulcer & $2.33 \pm 0.17^{\mathrm{a}}$ & $5.58 \pm 0.30^{\mathrm{c}}$ & $8.23 \pm 1.37^{\mathrm{c}}$ \\
\hline G. verum & $4.50 \pm 0.72^{\mathrm{b}}$ & $4.50 \pm 0.37^{\mathrm{b}}$ & $5.39 \pm 0.53^{\mathrm{b}}$
\end{tabular}

Values are mean \pm SEM $(n=6)$. Values with different superscript letters are significantly different $(P<0.05)$.

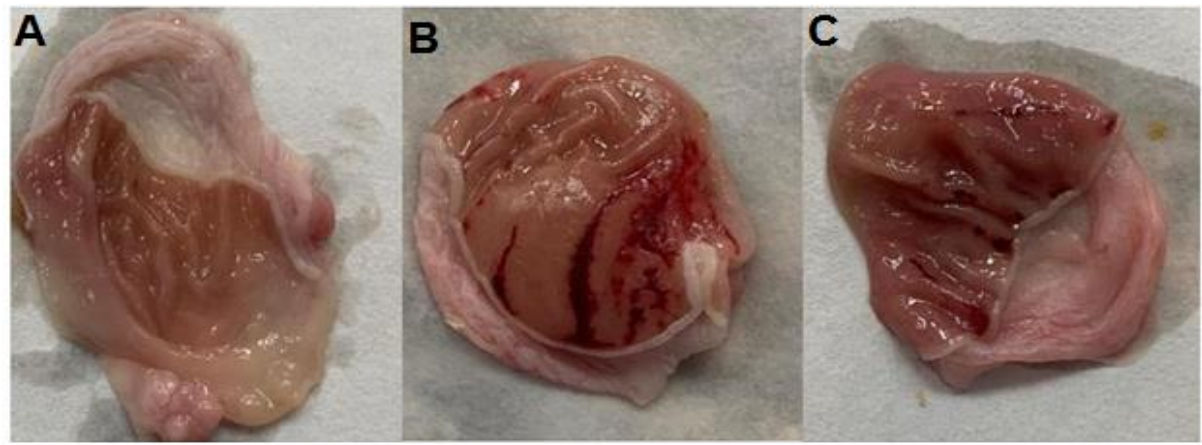

Figure 1. A, control rat stomach. B, model (ethanol and distilled water) rat stomach. $\mathbf{C}$, treated $(G$. verum) rat stomach. 
Increased gastric juice volume and gastric ulcer index in the ulcer group were attributed to increased acid secretion, edema, hemorrhage, necrosis, and inflammation [30]. Treatment with $G$. verum extract, however, revealed a significant rise in gastric acidity, in addition to a decline in gastric juice volume and gastric ulcer index

\subsection{The curative potency of $G$. verum on oxidative stress markers of gastric ulcer in rats.}

Gastric MDA and NO levels were significantly elevated (P < 0.05), while GSH, GST, and CAT levels were significantly decreased $(\mathrm{P}<0.05)$ after ethanol administration compared with the control group. It is well known that the pathogenesis of ethanol-induced gastric ulcers requires oxidative stress and reactive oxygen species (ROS). The ethanol-induced gastric ulcer is associated with increased purine degradation, leading to increased $\mathrm{O}_{2}$-radical development and increased lipid peroxidation mediated by ROS [7]. In line with previous research, the present finding showed that ethanol administration in rats contributed to a substantial increase in the amount of MDA in stomach tissue [31]. The amount of malondialdehyde in the gastric tissue was lowered by treatment with G. verum extract. Several experiments have shown that the scavenging of free radicals by antioxidant compounds avoids gastric ulcer ethanol-induced [32]. In ulcer-induced group depletion of GSH content, GST and CAT activities render gastric tissues more vulnerable to oxidative injury [7]. In addition, the treatment with G. verum extract showed substantial increases in GSH and CAT levels, specifying its antioxidant ability and further confirming that the compound has gastroprotective properties against ethanol-induced ulcer growth [33,34].In biological environments, nitric oxide (NO) is the principal reactive nitrogen species. NO can react with various oxidative molecules to create reactive nitrogen species, such as thiols and molecular oxygen (ROS) transition metals [35,36]. Here, a rise in the amount of NO in the ulcer group was noticed [7]. In contrast, the treatment with G. verum extract showed a substantial decrease in NO level protecting the stomach from more oxidative harm [34]. Treatment with G. verum extract reversed the changes induced by ethanol. Our results are consistent with different studies showing that the extraction of G. verum is an effective free radical scavenger in stomach tissue [33].

\begin{tabular}{|c|c|c|c|c|c|}
\hline Groups & MDA (nmol/g.tissue) & $\begin{array}{c}\text { NO } \\
(\mu \mathrm{mol} / \mathrm{g} . \mathrm{tissue})\end{array}$ & $\begin{array}{c}\text { GSH } \\
\text { (mg/g.tissue) }\end{array}$ & $\begin{array}{c}\text { CAT activity } \\
\text { (U/min) }\end{array}$ & $\begin{array}{c}\text { GST activity } \\
\text { (U/min) }\end{array}$ \\
\hline Control & $0.61 \pm 0.05^{\mathrm{a}}$ & $373.36 \pm 31.48^{a}$ & $1.85 \pm 0.10^{\mathrm{c}}$ & $200.37 \pm 6.31^{c}$ & $0.11 \pm 0.01^{\mathrm{c}}$ \\
\hline Ulcer & $1.53 \pm 0.08^{\mathrm{c}}$ & $882.56 \pm 47.56^{b}$ & $1.02 \pm 0.07^{\mathrm{a}}$ & $94.88 \pm 3.49^{a}$ & $0.04 \pm 0.00^{\mathrm{a}}$ \\
\hline $\begin{array}{c}G . \\
\text { verum }\end{array}$ & $0.94 \pm 0.06^{b}$ & $452.30 \pm 92.83^{\mathrm{a}}$ & $1.45 \pm 0.15^{b}$ & $160.05 \pm 10.12^{b}$ & $0.06 \pm 0.01^{b}$ \\
\hline
\end{tabular}

Values are mean $\pm \operatorname{SEM}(n=6)$. Values with different superscript letters are significantly different $(P<0.05)$.

\subsection{Histopathological analysis.}

Microscopic examination of gastric mucosa from the control group revealed normal histological structure, which showed normal mucosa containing gastric glands with connective tissue submucosa and muscular layer (Figure 2A). Meanwhile, the ulcer group revealed several alterations that extended into the affected mucosa and submucosa. The mucosa showed severe ulceration accompanied by extensive hemorrhages and necrosis with marked inflammatory cells infiltration. The submucosa was expanded by marked edema, congested blood vessels, and infiltration of inflammatory cells (Figure 2B). Administration of G. verum alleviated the induced gastric damages. The mucosa appeared normal structure in most examined sections; few individuals showed limited mucosal affection, which was illustrated by erosions, mild 
hemorrhages, and few mononuclear cell infiltrations (Figure 2C). The histological lesion score showed a significant enhancement in group $G$. verum compared to the ulcer group that scored the highest pathological destruction score (Figure 2D).
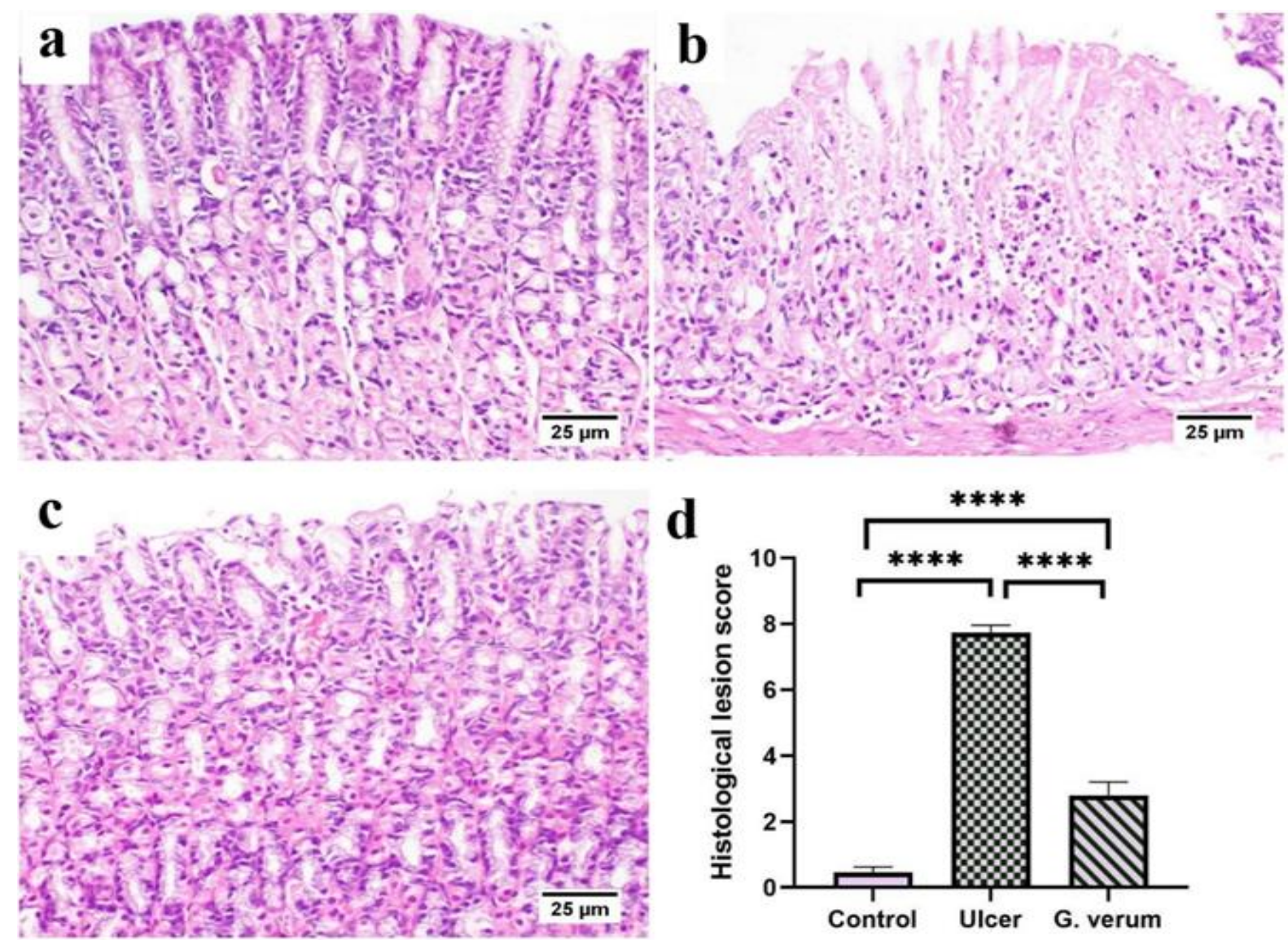

Figure 2. Histopathological assessment of rat gastric mucosa (H\&E stain). (a) Control group revealed the normal histological structure of gastric mucosa. (b) Ulcer group showing extensive necrosis accompanied by sloughing and destruction of lamina epithelial. (c) G. verum group showing mild sloughing of lining epithelium with few hemorrhages. (d) Histological lesion score. Data were expressed as means \pm SE. The significant difference is conducted as at $\mathrm{P}<0.05$.

The expression of NF- $\kappa \mathrm{B}$ p 65 and TNF- $\alpha$ was strongly detected in the affected mucosa of the ulcer group (Figure 3A). However, the G. verum group presented moderate positive staining for the aforementioned immune markers (Figure 3B). The area $\%$ of expression for NF- $\kappa$ B p65 and TNF- $\alpha$ showed a significant decrease in G. verum group compared to the ulcer group by $53.6 \%$ and $65.3 \%$, respectively (Figure 3C).

Our histological findings confirmed short-term exposure to ethanol-induced gastric damage, hemorrhagic erosions, and increased gastric ulcer index (UI): hemorrhagic degeneration, submucosal edema, shedding of gastric pits, and decreased glycoproteins in the gastric mucosal surface. Ethanol leads to overexpression of inflammatory factors NF- $\kappa \mathrm{B}$ p65 and TNF- $\alpha$. Meanwhile, a high level of inflammatory factors will prolong the pathological progress of ulcers. Therefore, G. verum inhibited NF- $\kappa \mathrm{B}$ signaling pathway by reducing the expression of pro-inflammatory cytokines and repressing the translocation of NF- $\kappa \mathrm{B}$. G. verum Up-regulate GSH, CAT, SOD, and the downregulation of MDA levels are associated with the inhibition of the NF- $\kappa \mathrm{B}$ pathway, which affects the expression of TNF- $\alpha$. 

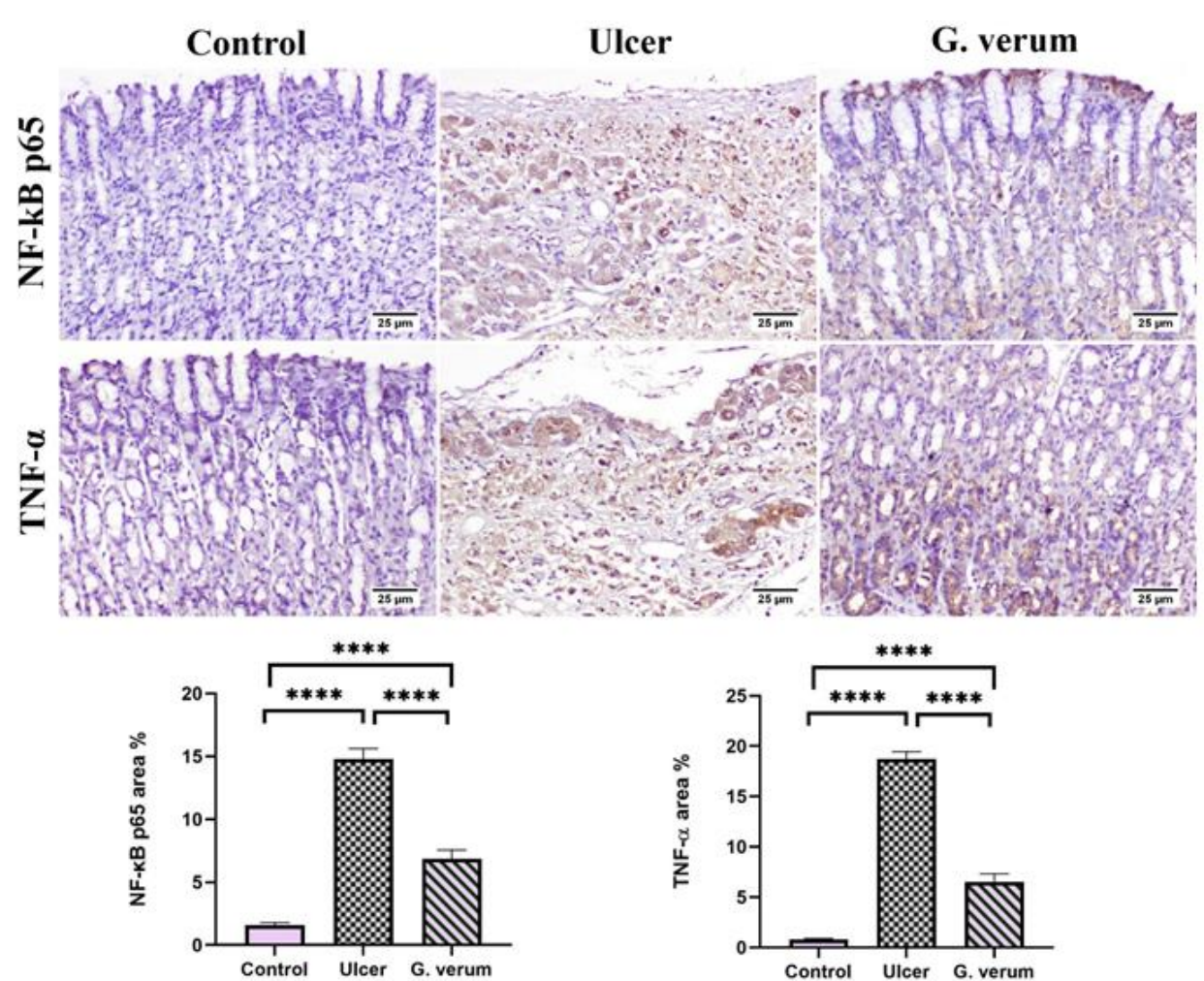

Figure 3. Immunohistochemical expression of NF- $\mathrm{BB}$ p 65 and TNF- $\alpha$ in the glandular gastric mucosa of different groups. Charts presenting IHC area \% expression of the immune markers positive staining. Data is expressed as means \pm SE. The significant difference is considered at $\mathrm{P}<0.05$.

\section{Conclusions}

The study's results clearly show that $G$. verum extract is a rich source of bioactive compounds with antiulcer potential. Preventing oxidative stress-mediated mucosal damage, limiting acid secretion, and suppressing pro-inflammatory cytokines are among the antiulcer mechanisms of $G$. verum extract.

\section{Funding}

No funding sources.

\section{Acknowledgments}

The authors extend their appreciation to the Deanship of Scientific Research at Cairo University, Egypt, for supporting the current work.

\section{Conflicts of Interest}

The authors declare no conflict of interest.

\section{References}

1. Kamada, T.; Satoh, K.; Itoh, T.; Iwamoto, J.; Okimoto, T.; Kanno, T.; Sugimoto, M. vidence-based clinical practice guidelines for peptic ulcer disease. $J$ Gastroenterol 2020, 56, 303-322, https://doi.org/.org/10.1007/s00535-021-01769-0.

2. Karampour, N.S.; Arzi, A.; Rezaie, A.; Pashmforoosh, M,; Kordi, F. Gastroprotective Effect of Zingerone on Ethanol-Induced Gastric Ulcers in Rats. Med 2019, 1-9, https://doi.org/10.3390/medicina55030064. 
3. Bellack, N. R.; Koehoorn, M. W.; MacNab, Y. C.; Morshed, M. G. A conceptual model of water's role as a reservoir in Helicobacter pylori transmission: A review of the evidence. Epidemiol. Infect. 2006, 134, 439449, https://doi.org/10.1017/S0950268806006005.

4. Rueda-Robles, A.; Rubio-Tomás, T.; Plaza-Diaz, J.; Álvarez-Mercado, A. Impact of Dietary Patterns on H. pylori Infection and the Modulation of Microbiota to Counteract Its Effect. A Narrative Review. Pathogens 2021, 10, 875, https://doi.org/10.3390/pathogens10070875.

5. Shukla, P. K.; Meena, A. S.; Dalal, K.; Canelas, C.; Samak, G.; Pierre, J. F.; Rao, R. Chronic stress and corticosterone exacerbate alcohol-induced tissue injury in the gut-liver-brain axis. Sci Rep 2021, 1826, 826, https://dx.doi.org/10.1038\%2Fs41598-020-80637-y.

6. Shin, M.-S.; Lee, J.; Lee, J. W.; Park, S. H.; Lee, K.; Choi, J. A.; Lee, J. S.; Kang, K. S. Anti-Inflammatory Effect of Artemisia argyi on Ethanol-Induced Gastric Ulcer: Analytical, In Vitro and In Vivo Studies for the Identification of Action Mechanism and Active Compounds. Plants (Basel) 2021, 12, 332, https://doi.org/10.3390/plants10020332.

7. Lakić, N. S.; Mimica-Dukić, N. M.; Isak, J. M.; Božin, B. N. Antioxidant properties of Galium verum L. (Rubiaceae) extracts. Cent. Eur. J. Biol. 2010, 5, 331-337, https://doi.org/10.2478/s11535-010-0022-4.

8. Gadekar, R.; Singour, P.; Chaurasiya, P.; Pawar, R.; Patil, U. A potential of some medicinal plants as an antiulcer agents. Pharmacogn. Rev. 2010, 4, 136-146, https://doi.org/10.4103/0973-7847.70906.

9. Mohamed, A. S.; Mahmoud, S. A.; Soliman, A. M.; Fahmy, S. R. Antitumor activity of saponin isolated from the sea cucumber, holothuria arenicola against ehrlich ascites carcinoma cells in swiss albino mice. Natural product research 2021, 35, 1928-1932, https://doi.org/10.1080/14786419.2019.1644633.

10. Bin Dajem, S.; Ali, S. B.; Abdelrady, O. G.; Salahaldin, N. M.; Soliman, A. M.; Kamal, Y. M.; Abdelazim, A. Y.; Mohamed, A. F.; Morsy, K.; Mohamed, A. S.; Fahmy, S. R. Allolobophora caliginosa coelomic fluid ameliorates gentamicin-induced hepatorenal toxicity in rats. Asian Pacific Journal of Tropical Biomedicine 2020, 10, 411-416, https://doi.org/10.4103/2221-1691.290132.

11. Sadek, S. A.; Hassanein, S. S.; Mohamed, A. S.; Soliman, A. M.; Fahmy, S. R. Echinochrome pigment extracted from sea urchin suppress the bacterial activity, inflammation, nociception, and oxidative stress resulted in the inhibition of renal injury in septic rats. Journal of food biochemistry 2021, 2021, e13729, https://doi.org/10.1111/jfbc.13729.

12. Mohamed, A. S.; Bin Dajem, S.; Al-Kahtani, M.; Ali, S. B.; Ibrahim, E.; Morsy, K.; Fahmy, S. R. Silver/chitosan nanocomposites induce physiological and histological changes in freshwater bivalve. Journal of Trace Elements in Medicine and Biology 2021, 65, 126719, https://doi.org/10.1016/j.jtemb.2021.126719.

13. Asiimwe, J. B.; Nagendrappa, P. B.; Atukunda, E. C.; Kamatenesi, M. M.; Nambozi, G.; Tolo, C. U.; Ogwang, P. E.; Sarki, A. M. Prevalence of the Use of Herbal Medicines among Patients with Cancer: A Systematic Review and Meta-Analysis. Evidence-Based Complementary and Alternative Medicine 2021, 2021, 18, https://doi.org/.org/10.1155/2021/9963038.

14. Palle, S. R.; Penchalaneni , J.; Lavudi, K.; Gaddam, S. A.; Kotakad, V. S.; Challagundala, V. N. Green Synthesis of Silver Nanoparticles by Leaf Extracts of Boerhavia erecta and Spectral Characterization and Their Antimicrobial, Antioxidant ad Cytotoxic Studies on Ovarian Cancer Cell Lines. Letters in Applied NanoBioScience 2020, 9, 1165 - 1176, https://doi.org/10.33263/LIANBS93.11651176.

15. Demirezer, L. Ö.; Gürbüz, F.; Güvenalp, Z.; STRÖCH, K.; Zeeck, A. Iridoids, flavonoids and monoterpene glycosides from Galium verum subsp. verum. Turkish journal of chemistry 2006, 30, 525-534, https://doi.org/=10.1.1.550.513\&rep=rep1\&type=pdf.

16. Bradic, J.; Zivkovic, V.; Srejovic, I.; Jakovljevic, V.; Petkovic, A.; Turnic, T. N.; Jeremic, J.; Jeremic, N.; Mitrovic, S.; Sobot, T.; Ponorac, N.; Ravic, M.; Tomovic, M. Protective effects of Galium verum L. extract against cardiac ischemia/reperfusion injury in spontaneously hypertensive rats. Oxidative medicine and cellular longevity 2019, 2019, 55-65, https://doi.org/10.1155/2019/4235405.

17. Mahmood, N., Nazir, R., Khan, M., Khaliq, A., Adnan, M., Ullah, M., \& Yang, H.. Antibacterial Activities, Phytochemical Screening and Metal Analysis of Medicinal Plants: Traditional Recipes Used against Diarrhea. Antibiotics (Basel, Switzerland) 2019, 8, 194, https://doi.org/.org/10.3390/antibiotics8040194.

18. Farag, R. S.; Abdel-Latif, M. S.; Abd El Baky, H. H.; \& Tawfeek, L. S.. Phytochemical screening and antioxidant activity of some medicinal plants' crude juices. Biotechnology reports (Amsterdam, Netherlands) 2020, 28, e00536, https://doi.org/10.1016/j.btre.2020.e00536.

19. Fecker, R.; Buda, V.; Alexa, E.; Avram, S.; Pavel, I. Z.; Muntean, D.; Cocan, I.; Watz, C.; Minda, D.; Dehelean, C. A.; Soica, C. \& Danciu, C. Phytochemical and Biological Screening of Oenothera Biennis L. Hydroalcoholic Extract. Biomolecules 2020, 10, 818, https://doi.org/10.3390/biom10060818.

20. Farag, R. S.; Abdel-Latif, M. S.; Abd El Baky, H. H. \& Tawfeek, L. S. Phytochemical screening and antioxidant activity of some medicinal plants' crude juices. Biotechnology reports (Amsterdam, Netherlands) 2020, 28, e00536, https://doi.org/10.1016/j.btre.2020.e00536.

21. Santos, B. L.; Oliveira, A. J.; Santos, I. V.; Duarte, M. C.; Cunha, P. S.; Dos Santos, D. M.; Silva, E.; Quintans Júnior, L. J. \& Santos, M.. Phytochemical screening and cardiovascular effects of the ethanol extract of Erythroxylum passerinum mart. Natural product research 2020, 1-5, https://doi.org/10.1080/14786419.2020.1844690. 
22. Chinedu, E.; Arome, D.; Ameh, F. S. A new method for determining acute toxicity in animal models. Toxicol Int 2013, 20, 224-226, https://doi.org/10.4103/0971-6580.121674.

23. Fahmy, S. R.; Mohamed, A. S.; Hosney, M.; Issa , H. A.; Hassanein, S. S.; Soliman, A. M. Hepatotoxicity effect of short-term Bradykinin potentiating factor in cholestatic rats. Toxicology letters 2019, 301, 73-78, https://doi.org/10.1016/j.toxlet.2018.11.006.

24. Maria, L.-R.; Lauro, F.-V.; Marcela, R.-N.; Francisco, D.-C.; Tomas, L.-G.; Virginia, M.-A.; Alejandara, G.E.; Magdalena, A.-R. M.; Regina, C.-C. Activity Exerted by Fluoro-2,4-Dioxaspiro[Bicyclo[3.3.1]Indene Derivative Against Ischemia/Reperfusion Injury. Letters in Applied NanoBioScience 2020, 9 , 1474- 1484, https://doi.org/10.33263/LIANBS94.14741484.

25. Farag, N. A.; Mohamed, A. S.; El Sayed, H. F.; Salah EL-Din, E. Y.; Tawfik, A. A. Echinochrome Pigment Improves Male Rats' Fertility. The Natural Products Journal 2020, 10, 1, https://doi.org/10.2174/22103155109992011162055.

26. Mohamed, A. S. Echinochrome Exhibits Antitumor Activity against Ehrlich Ascites Carcinoma in Swiss Albino Mice. Nutrition and Cancer 2021, 73, 124-132, https://doi.org/10.1080/01635581.2020.1737152.

27. Main , I. H. M.; White, B. R. The effects of $\mathrm{E}$ and A prostaglandins on gastric mucosal blood flow and acid secretion in the rat. British Journal of pharmacology 1975, 53, 217-224, https://doi.org/10.1111/j.14765381.1973.tb17253.x.

28. Schmidt, M.; Polednik, C.; Roller, J.; Hagen, R. Galium verum aqueous extract strongly inhibits the motility of head and neck cancer cell lines and protects mucosal keratinocytes against toxic DNA damage. Oncol. Rep. 2014, 296-1302, https://doi.org/10.3892/or.2014.3316.

29. Rahman, Z.; Dwivedi, D. K.; Jena, G. B. Ethanol-induced gastric ulcer in rats and intervention of tertbutylhydroquinone: Involvement of Nrf2/HO-1 signalling pathway. HET 2020, 39, 547-562, https://doi.org/10.1177/0960327119895559.

30. Suzuki, H.; Nishizawa, T.; Tsugawa, H.; Mogami, H.; Hibi, T. Roles of oxidative stress in stomach disorders. J Clin Biochem Nutr 2012, 50, 35-39, https://doi.org/10.3164/jcbn.11-115SR.

31. Cemek, M.; Yilmaz, E.; Büyükokuroĝlu, M. E. Protective effect of Matricaria chamomilla on ethanol-induced acute gastric mucosal injury in rats. Pharm. Biol. 2010, 48, 757-763, https://doi.org/ 10.3109/13880200903296147.

32. Farcas, A. D.; Mot, A. C.; Zagrean-Tuza, C.; Toma, V.; Cimpoiu, C.; Hosu, A.; Parvu, M.; Roman, I.; SilaghiDumitrescu, R. Chemo-mapping and biochemical-modulatory and antioxidant/prooxidant effect of galium verum extract during acute restraint and dark stress in female rats. PLoS One 2018, 13, 1-18, https://doi.org/10.1371/journal.pone.0200022.

33. Tava, A.; Biazzi, E.; Ronga, D. \& Avato, P.. Identification of the Volatile Components of Galium verum L. and Cruciata leavipes Opiz from the Western Italian Alps. Molecules (Basel, Switzerland) 2020, 25, 2333, https://doi.org/10.3390/molecules25102333.

34. Kar, S.; Kavdia, M. Endothelial NO and $\mathrm{O} 2$ production rates differentially regulate oxidative, nitroxidative, and nitrosative stress in the microcirculation. Free Radic. Biol. Med. 2013, 63, 161-174, https://doi.org/10.1016/j.freeradbiomed.2013.04.024.

35. Mamdouh, S.; Mohamed, A. S.; Mohamed, H. A.; Fahmy, W. S. The Effect of Zinc Concentration on Physiological, Immunological, and Histological Changes in Crayfish (Procambarus clarkii) as Bio-indicator for Environment Quality Criteria. Biological Trace Element Research 2021, https://doi.org/10.1007/s12011021-02653-x. 